\title{
RECENSIÓN AL LIBRO "LA CONDICIÓN RESOLUTORIA CONSIGNADA EN EL CONTRATO DE TRABAJO” DE ALICIA VILLALBA SÁNCHEZ.
}

\author{
Emma Rodríguez Rodríguez \\ Profesora Contratada Doctora (Acreditada a TU) \\ Derecho del trabajo y la Seguridad Social. \\ Universidad de Vigo
}

La obra que se presenta es el resultado de la investigación que dio origen a la tesis doctoral que defendió con éxito su autora, Alicia Villalba SÁNCHEZ. Es, por lo tanto, un primer trabajo o una "puesta de largo" de esta brillante investigadora y joven profesora, en la actualidad. Ahora bien, no por ello - o precisamente por esta causaaborda de manera reflexiva, profunda y ortodoxa, a la vez que amena, una de las figuras de las que se ha ocupado la doctrina laboralista desde sus mismos orígenes, cuando se desliga del derecho civil como materia de estudio autónoma, la condición resolutoria consignada en el contrato de trabajo.

Este trabajo se estructura en un capítulo introductorio, otro apartado final "a modo de recapitulación" y tres grandes Capítulos que albergan las temáticas principales del trabajo. Así, tras un afectuoso y, a la vez, riguroso Prólogo de la Directora de la tesis, la Profesora Consuelo FERREIRo REgUeIRo, la autora introduce al lector en el propio origen de la condición resolutoria consignada en el contrato de trabajo que no es otro que la autonomía individual de la voluntad de las partes. Es decir, se trata de una figura clásica de la materia de obligaciones y contratos de nuestro ordenamiento jurídico y, por este motivo, también aparece en las primeras normas laborales del Derecho del Trabajo español. La principal diferencia en el ámbito laboral respecto del derecho común es que esa regulación protege a una de las partes del contrato al considerarse más débil que la otra, de tal forma que se protege al trabajador frente al empresario.

En este Capítulo introductorio la autora establece una primera distinción entre las causas resolutorias consignadas en el contrato, diferenciando entre las que prevé el artículo 49.1.b) ET, que son las consideradas cláusulas extintivas stricto sensu, de aquéllas que carecen de una previsión concreta, pero que igualmente justifican la extinción de manera indirecta, a través de lo que supone una condición resolutoria tácita. De la misma manera, cabe diferenciar la causa extintiva que deriva directamente de la previsión sobre el período de prueba del artículo 14 ET. Además, en general, las condiciones resolutorias pueden resultar ilícitas si no están válidamente consignadas en el contrato, bien por contravenir lo dispuesto en la normativa legal o convencional, o porque se produzca un "abuso de derecho por parte del empresario". En tales casos, resultará de aplicación la norma que se pretende eludir. 
Resulta, por lo tanto, acertada y muy importante la opción del legislador laboral de dejar en manos de la autonomía individual de la voluntad estas posibilidades extintivas del contrato que ellas mismas se comprometen a cumplir, no obstante, la autora resalta la importancia de la normativa estatal y de la autonomía colectiva frente a la erosión de las condiciones laborales a través de la habitual contratación en "masa" en la que se impone la voluntad empresarial y podría dar lugar a estipulaciones leoninas. En este punto, la Profesora Alicia Villalba bebe de las fuentes del derecho comparado clásico, tanto estudiando a doctrina italiana como francesa para reflexionar acerca de nuestra propia regulación civil respecto del principio de buena fe y la configuración del contrato de trabajo como contrato de adhesión. En este punto se impone una reflexión sobre el propio control de legalidad de las causas resolutorias del contrato, para lo que la autora, de nuevo acude al derecho comparado, en este caso el derecho alemán, para referirse a la propia esencia del derecho administrativo sancionador que se ha incorporado al ordenamiento español.

Siguiendo la estructura que se ha descrito, el Capítulo I está dedicado a las cláusulas relativas a la extinción del contrato de trabajo consignadas en el artículo 49.1.b) ET. Se agrupan en torno a tres tipos en función de su propio contenido. En primer lugar, las cláusulas que fijan un rendimiento mínimo que pueden presentar problemas jurídicos para su admisión como condición resolutoria autorizada directamente a través del artículo 49.1.b) ET. Distinto es el supuesto en el que el rendimiento mínimo se establece como una causa de extinción contractual equiparable a las del despido disciplinario. O, incluso, que se pacte un determinado rendimiento como causa autónoma respecto del despido disciplinario.

En el primer caso, de nuevo la buena fe y el abuso de derecho de la parte más fuerte de la relación contractual desvirtúa su admisión como causa genérica de extinción. Ahora bien, respecto del despido disciplinario la autora distingue entre la falta de rendimiento como manifestación de la transgresión de la buena fe contractual o, por ejemplo, como una consecuencia directa de las faltas de asistencia o de puntualidad en el puesto de trabajo, de la estipulación contractual específica que califique como infracción laboral no alcanzar un determinado rendimiento. Es decir, hay que distinguir entre la que se deriva de las previstas por la ley como causas del despido disciplinario, ex artículo 54 ET, de aquéllas que autónomamente las partes han establecido en una determinada relación laboral y que, en caso de producirse, efectivamente implicará la posibilidad de que el empresario haga uso de su potestad disciplinaria.

El siguiente grupo de cláusulas de extinción se refieren a que condicionan la vigencia del contrato de trabajo a la obtención de una titulación académica o profesional o a la obtención o mantenimiento de una habilitación administrativa. Pues bien, como analiza 
magistralmente la autora -con citas de pronunciamientos internos, europeos y hasta estadounidenses- la autonomía de la causa extintiva de este tipo de cláusulas para su validez requiere tres circunstancias concretas, sin las cuales la condición resolutoria se reputará ilícita, siendo nula la causa por la que se haya consignado en el contrato.

En primer lugar, que la titulación o el permiso sean necesarios para el desempeño de las funciones objeto del contrato. En segundo lugar, que dichas funciones sean efectivamente ejecutadas por el trabajador. Y, por último, que la ausencia o pérdida del permiso o titulación sea imputable al trabajador. Sólo la concurrencia de estos tres elementos puede llegar a justificar la sujeción al régimen extintivo del artículo 49.1.b) ET, dada la responsabilidad que el trabajador asume con respecto a disponer de esa titulación o permiso habilitante para el desempeño de la prestación de trabajo.

El tercer y último grupo de cláusulas que detecta la autora se refieren a las que condicionan la vigencia del contrato de trabajo a la subcontratación de obras o servicios. Pues bien, partiendo de que el empresario que opta por la descentralización de su negocio se transforma en el adquirente de los bienes y servicios del empresario contratista, será ese quién asume la condición de empleador respecto de los trabajadores que efectivamente desarrollen la actividad. No obstante, el derecho laboral conlleva una tutela reforzada del contrato de trabajo, de manera que la vigencia de las obligaciones contractuales entre el empresario principal y los trabajadores también perdura, con todos sus efectos. De este modo, la propia temporalidad contractual se justificará por esta descentralización productiva y las obligaciones laborales limitadas en el tiempo, que se trasladan al subcontratista.

Así, ViLlalba se refiere a tres momentos y circunstancias que pueden relacionarse con este tipo de cláusulas. Las incardinadas en contratos de trabajo para obra o servicio determinado, son las primeras y más evidentes en lo que se refiere a la propia limitación de la vigencia del contrato a las necesidades concretas de la producción. En segundo lugar, las incardinadas en los contratos de trabajo de duración indefinida que se relacionan, fundamentalmente con cambios en los procesos productivos. Y, finalmente, las cláusulas que condicionan la pervivencia del contrato de trabajo a la vigencia de una concesión administrativa.

Para finalizar este Capítulo, la autora analiza la forma y las consecuencias de la extinción del contrato, refiriéndose a las consecuencias laborales, como la indemnización prevista legalmente, así como en el ámbito de la Seguridad Social.

El Capítulo siguiente aborda el estudio de una causa resolutoria expresa, pero con peculiaridades muy importantes, como es la cláusula por la cual se consigna en el 
período de prueba. Tras una breve evolución del propio concepto del período de prueba, se analiza el contenido de esta cláusula, partiendo de una disyuntiva: ¿es una condición resolutoria o se trata del derecho al desistimiento? La autora analiza profusamente y de manera ejemplar ambas hipótesis que va aludiendo y estudiando diversos indicios que nos llevan a una conclusión final, pero no cerrada ni excluyente. Ahora bien, ella misma nos señala, de manera muy acertada, que en este tipo de cláusulas se hace patente la ausencia de reciprocidad manifestada en alguna disposición convencional que le concede al empresario, y no al trabajador, la facultad de renunciar al propio período de prueba. En consecuencia, concluye que "ha de cuestionarse carácter bilateral con el que el artículo 14 ET pretende revestir el pacto del período de prueba".

A continuación, se analizan los aspectos formales para la incorporación del período de prueba al contrato, tanto la forma escrita como el momento de la suscripción. Pero, sin duda, una de las partes centrales del libro se refiere a la polémica cuestión sobre la duración del período de prueba que, tras la Ley 3/2012 fue objeto de profusos pronunciamientos de judiciales que cuentan con importantes Votos particulares que han sido estudiados por la doctrina laboralista.

Tras este profuso análisis - con referencia a doctrina y jurisprudencia comparada- se analiza las obligaciones que conlleva el cumplimiento de la condición resolutoria. Con carácter principal, se exige el deber de experimentación y no superación del ensayo, pues de lo contrario la propia extinción devendría nula y por no puesta. Este aparado se completa con el último del Capítulo sobre la forma y las consecuencias de la extinción del contrato durante el período de prueba.

Por último, el Capítulo III se dedica al estudio de la condición resolutoria tácita, es decir, la posibilidad y la justificación del empresario para acogerse a las cláusulas de reserva de modificación del contrato de trabajo. El profuso y detallado estudio que se recoge en la obra comienza analizando la onerosidad sobrevenida del contrato de trabajo como justificación para aplicar la cláusula rebus sic stantibus y modificar las condiciones sustanciales de trabajo, incluso a través de pactos novatorios, más limitados al ámbito civil de los contratos.

En definitiva, estas causas debidamente justificadas conllevan la modificación de las condiciones del contrato laboral, lo que no se produce, y, por lo tanto, carecerán de eficacia extintiva, cuando se lleve a cabo un despido disciplinario u otro tipo de resolución judicial, como tras la impugnación de las modificaciones sustanciales. Asimismo, el trabajador puede, ante esas cláusulas de reserva de modificación rescindir el contrato de trabajo o solicitar la resolución del mismo. 
El último apartado de este último Capítulo se refiere a la tipología de las cláusulas de reserva de modificación. La autora, tal y como había hecho en apartados precedentes, realiza un esfuerzo sistemático muy importante y las agrupa en función de diez ítems: el momento de su suscripción, su carácter negociado o impuesto, su origen acordado o conflictual, su formulación expresa o tácita, su concreción, su carácter favorable o desfavorable para el trabajador, en función de los sujetos, de las fuentes que recoge la cláusula y en función de la condición regulada. Se trata, en definitiva, de una análisis minucioso y ordenado de la regulación convencional y de pronunciamientos judiciales que otorgan a esta obra un gran valor, tanto para el conocimiento teórico, como de la práctica de quién se acerca a esta complicadísima figura de las condiciones resolutorias en el contrato de trabajo.

Para concluir, VillalbA, nos deja unas conclusiones sucintas y muy interesantes, a modo de reflexión final o de "recapitulación", como ella lo denomina. Efectivamente, pone de manifiesto afirmaciones -que compartimos- como es que el recobrado protagonismo del contrato de trabajo y de los pactos individuales, como fuentes reguladoras de las condiciones laborales, en concreto, de su propia extinción. Critica que las cláusulas referidas incrementan la inseguridad jurídica del trabajador y, en consecuencia, llama a la negociación colectiva a desempeñar el papel esencial en la protección del trabajador, sobre todo, homogeneizando las condiciones de trabajo e identificar aquéllas que, por su abuso de derecho o fraude en la regulación, pasarían a ser calificadas como ilegales.

En definitiva, este libro cuenta con un importante grado de análisis realizado con la ortodoxia que caracteriza a misma Profesora VillalbA. Constituye un instrumento de información, formación y reflexión sobre cuestiones derivadas de las condiciones resolutorias en el contrato de trabajo, entendidas como factor relevante en el ámbito de las relaciones de trabajo. Es pues, una obra de excelente calidad que resultará fundamental a cuantas personas estén interesadas en su temática, tanto desde una perspectiva teórica como práctica. 